\title{
AOR
}

Selected Papers of \#AolR2019:

The $20^{\text {th }}$ Annual Conference of the Association of Internet Researchers Brisbane, Australia / 2-5 October 2019

\section{DOUBT AND DISENGAGEMENT: TECHNOLOGIES AND PRACTICES OF DIGITAL DISCONNECTION}

\author{
Introductory Statement
}

When people distrust media systems, one response is to disconnect. This emergent theme within internet research encompasses technologies, practices, discourses, and politics of disconnection. Burgeoning scholarly interest in these areas has been partly driven by recognition that media and communication scholarship has traditionally overlooked such issues due to its long-standing focus on forms and technologies of connection. It has also been driven by recognition of the changing nature of people's everyday engagement with online and digital media. As networked communication technologies become ubiquitous, finding ways to connect-whether to technologies, ideas, or each other-is less the challenge; rather, is it finding ways to manage, limit, and resist connections that is most urgent.

To further these discussions of disconnection, this panel draws together four investigations into technologies and practices of digital disconnection. In response to the conference theme 'trust in the system', each paper interrogates a different form of disconnection and considers the various elements of trust and/or mistrust that are entangled with these phenomena.

The first two papers focus on forms of disconnection that center around avoidance. The first paper takes up the problem of digital propaganda and the associated declining trust in online media systems. It considers how forms of informational avoidance might open new spaces for resistance to propaganda and misinformation. The second paper considers the challenge of managing personal availability in a context where mobile communication — particularly messaging apps_create expectations of continual availability. It investigates the partly duplicitous practices that young adults use to avoid other people without causing relational tension or conflict.

In both papers, languages broadly conceived (including programming languages)

Suggested Citation (APA): Mannell, K., Plaut, E., Kania-Lundholm, M. \& A. Beattie. (2019, October 2-5). Doubt and disengagement: Technologies and practices of digital disconnection. Panel presented at AolR 2019: The $20^{\text {th }}$ Annual Conference of the Association of Internet Researchers. Brisbane, Australia: AolR. Retrieved from http://spir.aoir.org. 
provide the central mechanism for disconnection. The first proposes strategic illiteracies as a way out of the double-bind caused by growing mistrust in media systems, as scepticism leads either to acceptance of conspiracy or to an impossible program of exhaustively vetting information. Drawing on parallels with anti-colonial resistance to literacy in colonizers' languages, the paper proposes strategic illiteracy as an alternative to digital literacy initiatives-suggesting that avoidance may provide a means of mitigating misinformation without the burden of developing impossible levels of expertise.

The second paper analyses language drawn from interviews with young adults about their messaging practices, outlining a range of discursive strategies that participants deployed to limit their availability to others. The paper argues that these discursive avoidance practices were enabled by a system of implicit interpersonal trust that gave participants confidence that their strategies would be understood and respected by others.

The remaining two papers consider how neoliberal discourses of self-improvement are involved in the impetus to disconnect and shape the forms that disconnection takes. In contrast to the first two papers, where disconnection is understood through linguistic processes and metaphors, the disconnections in these papers are based around consumption choices and technology design.

The third paper argues that, in many cases, digital disconnection is incorporated into the neoliberal capitalist system rather than resisting it. The paper outlines how forms of disconnection that are enacted through conspicuous consumption (or non-consumption) are premised upon a logic of cool refusal, where modes of resistance become choices within a market.

The fourth paper takes up these arguments via a case of the anti-distraction app Siempo. Drawing on interviews and the app-walk-through method, the paper interrogates the features within Siempo, unpacking how their design relates to the app's promise of emancipation from smartphone addiction. It argues that the app is ultimately less about breaking connections and more about redirecting online behaviours towards aspirational ends.

Both papers view these forms of disconnection as, at least partly, a reflection of growing distrust in dominant modes of technology design, specifically their cognitive impacts. In response, the disconnective practices and technologies discussed in these papers place their trust in individualised solutions. Both papers consider the grounds on which this trust is founded and question the individualisation of large-scale social problems, both in terms of effectiveness and implications for equality.

Taken as a whole, this panel raises important questions about the viability and politics of various forms of disconnection. It contributes to scholarly debate around disconnection by considering new forms of disconnection, their role in our contemporary media environment, and the forms of trust and mistrust they reflect. 


\title{
'STRATEGIC ILLITERACIES': COMPUTATIONAL PROPAGANDA AND THE LEGACY OF RESISTANCE TO ORTHOGRAPHIC IMPERIALISM
}

\author{
Ethan Plaut \\ University of Auckland, New Zealand
}

There is no easy fix for computational propaganda. Some solutions, such as legislation, function at the level of structural reform to untrustworthy media systems. At the level of the individual, vast amounts of funding, effort, and hope have been invested in education-based initiatives to help people parse, navigate, and participate in our mediated public. Some even suggest that "education is the only antidote to fake news" (Davies, 2018). This article considers the possibilities and limitations of these educational initiatives, which are broadly understood as 'literacies', and proposes an alternative approach of 'strategic illiteracies'.

Many things have been called literacies: cultural literacy, visual literacy, critical literacy, television literacy. Computer literacy was big in the 1980s. Later came internet literacy, procedural literacy and computational literacy (Leu, Kinzer, Coiro, \& Cammack, 2004; Vee, 2013). These literacies are proposed as solutions to many problems, and in some specific contexts, they may be effective (e.g., Jeong, Cho, \& Hwang, 2012). This paper is focused on the problems of digital propaganda and two distinct pedagogical movements against it. First, "media literacy" programs teach laypeople media skills including evaluation of messages in terms of origin, intention, facticity, and other ostensible qualities. Second, "computational literacy" and "computational thinking" go beyond the ability to code, arguing for computation as a general method of problem solving.

Our trust in media systems can be used against us, but so can our distrust. Media literacy initiatives that teach people to distrust what they read online cut multiple ways. This may lead to better-informed citizens in many cases. Unfortunately, independent research is often burdensome or impracticable for individuals. If media literacy initiatives teach people to trust their own ad hoc investigations (often simply Google searches) more than they trust journalists and other professionals, we risk exacerbating the collapse of trust brought about by disinformation (boyd, 2017, 2018). Conspiracy theories, which promise dramatically unmasked truths, similarly prey on this phony sophistication (Andrejevic, 2013, pp. 111-135). Members of the public cannot develop the expertise and devote the resources to conduct serious investigations into the issues of the day. Likewise, training journalists in computation may better equip them to handle certain problems, but computational literacy is not a panacea for our propagandized newsmedia ecosystem. Under certain conditions, digital literacies movements may even make journalists' problems worse. 
When computational propaganda seeks to overwhelm, confuse, and simply exhaust, perhaps 'literacies' are not the right response. Herculean efforts to make sense of nonsense precisely play into the hands of propagandists. The sophistication and volume of computational propaganda may in some sense be new, but people can draw on strategies developed long ago for resisting media that threaten to overwhelm culture. While resistance to technological literacies may be derided as ludditism and philistinism, this paper proposes 'strategic illiteracies' as a different lineage of thought and action. The assumption that literacy is a basic skill — and therefore neutral, a useful tool whatever your values - makes it a perfect placeholder or metaphor for other skills, technical and otherwise (Wysocki \& Johnson-Eilola, 1999). But this naïve concept of literacy masks its power relations. Throughout history, people have protected their cultures by resisting not only foreign tongues but also foreign alphabets. This has been especially true with alphabets associated with imperial power, from the Greek alphabet in classical antiquity (Colvin, 2014) and Chinese characters across East Asia (Takayama, 1995) to the Latin alphabet later used by British, Spanish, French, and other colonial powers to subjugate indigenous and other local cultures around the world. By refusing to learn colonizers' languages and alphabets, people have cultivated these 'strategic illiteracies' to resist domination and protect their own culture.

To analyse this counterintuitive notion that problematic media might be met not with additional literacies, but with a strategic lack thereof, this paper turns to the economic concept of 'commitment devices' or 'Ulysses pacts,' ways in which we constrain our own future actions (e.g., Elster, 1979, 2000; Schelling, 1984). For example, people use retirement savings to prevent themselves from spending. Similarly, people use specialized software to block their own access to social media and avoid distractions (Plaut, 2015). Strategic illiteracies are peculiar and profound Ulysses pacts, forms of 'strategic ignorance' (Carrillo \& Mariotti, 2000) that go beyond mere transactions to existential resistance, ways we choose to think and be - or not.

It isn't always necessary or right to understand the world in someone else's terms, through someone else's media. But it can be hard to resist. Of the situation in India, Aijaz Ahmad writes: "One cannot reject English now, on the basis of its initially colonial insertion, any more than one can boycott the railways for the same reason" (1994, p. 77). Digital media approach this infrastructural stage. Neither individuals' technical literacies nor their rejection thereof will fix untrustworthy systems. Having reached this conclusion, though, people might at least be relieved of the unrealistic expectation that they learn to make sense of nonsense.

\section{References}

Ahmad, A. (1994). In Theory: Classes, Nations, Literatures. London: Verso. 
Andrejevic, M. (2013). Infoglut: How Too Much Information Is Changing the Way We Think and Know. Routledge.

boyd, danah. (2017, January 5). Did Media Literacy Backfire? Retrieved April 4, 2018, from https://points.datasociety.net/did-media-literacy-backfire-7418c084d88d

boyd, danah. (2018, March 9). You Think You Want Media Literacy... Do You? Retrieved April 4, 2018, from https://points.datasociety.net/you-think-you-want-medialiteracy-do-you-7cad6af18ec2

Carrillo, J. D., \& Mariotti, T. (2000). Strategic ignorance as a self-disciplining device. The Review of Economic Studies, 67(3), 529-544.

Cazden, C., Cope, B., Fairclough, N., Gee, J., \& al, et. (1996). A pedagogy of multiliteracies: Designing social futures. Harvard Educational Review; Cambridge, 66(1), 60 .

Colvin, S. (2014). A Brief History of Ancient Greek (1 edition). Chichester, West Sussex; Malden, MA: Wiley-Blackwell.

Davies, H. (2018, February 19). Why education is the only antidote to fake news. New Statesman. Retrieved from http://tech.newstatesman.com/guest-opinion/educationantidote-fake-news

Elster, J. (1979). Ulysses and the Sirens: Studies in Rationality and Irrationality. Cambridge, England: Cambridge University Press.

Elster, J. (2000). Ulysses Unbound: Studies in Rationality, Precommitment, and Constraints. Cambridge, England: Cambridge University Press.

Jeong, S.-H., Cho, H., \& Hwang, Y. (2012). Media literacy interventions: A meta-analytic review. Journal of Communication, 62(3), 454-472.

Jewitt, C., \& Kress, G. R. (2003). Multimodal Literacy. P. Lang.

Leu, D. J., Kinzer, C. K., Coiro, J. L., \& Cammack, D. W. (2004). Toward a theory of new literacies emerging from the Internet and other information and communication technologies. Theoretical Models and Processes of Reading, 5(1), 1570-1613.

Plaut, E. R. (2015). Technologies of avoidance: The swear jar and the cell phone. First Monday, 20(11).

Schelling, T. C. (1984). Self-Command in Practice, in Policy, and in a Theory of Rational Choice. The American Economic Review, 74(2), 1-11.

Takayama, K. P. (1995). Adaptation and resistance to Chinese literary hegemony: Korea and Japan. International Journal of Politics, Culture, and Society, 8(3), 467-488. 
Vee, A. (2013). Understanding Computer Programming as a Literacy. Literacy in Composition Studies, 1(2), 42-64. https://doi.org/10.21623/1.1.2.4

Wysocki, A. F., \& Johnson-Eilola, J. (1999). Blinded by the letter: Why are we using literacy as a metaphor for everything else? Passions, Pedagogies, and 21st Century Technologies, 349-68. 


\section{'SORRY JUST SAW YOUR MESSAGE!': DISCURSIVE STRATEGIES FOR DISCONNECTING VIA MOBILE MESSAGING APPS}

Kate Mannell

University of Melbourne, Australia

Scholars have recently begun to focus on how people not only connect through online platforms, but also limit and withhold connections (Light, 2014; Karppi, 2018; Morrison \& Gomez, 2014). Ben Light (2014) for instance, demonstrates how using social media platforms involves disconnective practices, such as stalking other users and restricting the visibility of posts, as much as it involves connective practices, such as friending, liking, and sharing. While these disconnective practices are enabled by social media platforms, they also resist the imperative to connect that underpins the plaforms' design.

Research suggests that disconnective practices may be especially significant within young adults' use of mobile messaging apps, such as Facebook Messenger and WhatsApp. Firstly, young adults are typically heavy users of mobile messaging (Lenhart, 2012). Further, the ubiquity of mobile devices has led to an expectation that people are continually available, which, in turn, means that people must actively work to manage their availability to others (Ling, 2016; Burchell, 2017a; 2017b). As typically heavy users of messaging, young adults must continually work to manage their mobilemediated availability to others. Lastly, being able to limit availability to friends can be important to the wellbeing of young adults. Research by Hall and Baym (2012), for instance, found that when young people were unable to limit their mobile contact with friends it could produce negative feelings of over-dependence and entrapment.

Accordingly, the expectations of continual availability scripted into mobile communication together with the relational implications of mobile connections in the lives of young people, suggest that disconnective practices will be especially significant within young adults' use of messaging apps.

To better understand how young adults navigate these complex conditions, this paper investigates the discursive strategies they use when messaging in order to avoid or delay interactions with friends. These discursive strategies include using written text, images, and silence as tools for resisting and reducing connections. To understand these practices, the paper draws on data from an in-depth interview study of young adults use of messaging apps. For this study, 24 young adults (13 female, 11 male) were interviewed twice over a period of six months. They were also asked to provide a sample of messages that were then used as a prompt within the interviews. Participants were aged between aged 18-30 and were living in Melbourne at the time of the interviews. 
The findings from these interviews reveal five key discursive strategies for limiting and reducing connection: vagueness, closers, deception, dissuasion, and silence. Vagueness refers to the practice of sending intentionally ambiguous messages as a means of controlling availability; closers refers to techniques used to end a conversation; deception refers to the practice of lying when accounting for past or future unavailability; dissuasion refers to the use of language to dissuade an interlocutor from continuing a conversation; and silence refers to the practice of not responding to a message as a means of enforcing boundaries. These categories are not mutually exclusive-for instance, a person might use vagueness when being deceptive. The strategies can also be used in combination with other technical or temporal mechanisms for restricting availability, such as changing notification settings or altering the speed of reply.

Analysing these practices through Goffman's (1956; 1967) frameworks of impression management, face-work, and ritual interaction highlights the often delicate interpersonal dynamics involved in using discursive strategies to limit and reduce connections. It demonstrates that discursive strategies are not just ways of reducing connection but are always attempts to do so in a manner that is tactful—that protects the face of the person using the strategy and the face of the person it is directed toward. For instance, when sending minimal messages to discourage a reply (dissuasion) participants were often trying to signal disinterest without having to engage in forms of explicit rejection that may be hurtful to others or reflect poorly on them. That is not to say, however, that these strategies are without risk or were always successful in my participants' accounts: tact can be ignored, fronts can be challenged, and attempts at impression management can fail.

While driven, in part, by relational dynamics that are also present in face-to-face interaction, the accounts of my participants demonstrate that these discursive strategies are also shaped by the affordances of mobile devices and messaging apps. For instance, messaging's lack of meta-textual cues-like tone of voice or facial expression-results in a semantic instability that often causes misunderstandings. Participants were highly aware of this semantic instability and, when using vagueness to control their availability, they strategically leveraged it to create messages that could be interpreted in multiple ways. Similarly, when using deception to account for their unavailability, participants described drawing on the asynchronicity of messaging, which gave them time to craft a viable excuse, and the lack of meta-textual cues, which made is easier to carry out the lie as they did not have to control their voice or body language.

The success of these discursive strategies often relied on systems of trust. Participants described the importance of implicit agreement between friends that managing mobile availability was difficult, and that discursive strategies for doing so would not be challenged. This is akin to Goffman's (1959, p. 230-233) descriptions of the collusion 
between performer and audience, whereby the audience accepts and supports a performance even when they aware that it is face-saving front. Audience collusion was particularly evident in participants' descriptions of being on the receiving end of the same discursive strategies that they employed. They described recognising that their interlocutor was trying to save face, in the same manner that they often did, and leaving space for them to do so successfully by not interrogating or undermining the discursive strategies they had deployed.

These discursive strategies reveal that, contrary to popular characterisations of young adults as hyper-connected, many young adults have a range of connectionmanagement techniques that they use to reduce their connections to others. Furthermore, these techniques are often supported by broader social agreements about the difficulty of managing availability and the importance of discursive strategies in doing so tactfully.

\section{References}

Burchell, K. (2017a). Everyday communication management and perceptions of use: How media users limit and shape their social world. Convergence, 23(4), 409-242. doi:10.1177/1354856517700382

Burchell, K. (2017b). Finding time for Goffman: When absence is more telling than presence. In T. Markham \& S. Rodgers (Eds.), Conditions of Mediation:

phenomenological perspectives on media (pp. 185-196). New York: Peter Lang

Goffman, E. (1967). Interaction Ritual. New York: Anchor Books.

Goffman, E. (1956). The presentation of self in everyday life. New York: Anchor Books.

Hall, J., \& Baym, N. (2012). Calling and texting (too much): Mobile maintenance expectations,(over) dependence, entrapment, and friendship satisfaction. New Media \& Society, 14(2), 316-331. doi:10.1177/1461444811415047

Lenhart, A. (2012). Teens, smartphones \& texting. Pew Internet \& American Life Project 21, 1-34. Available at: http://www.pewinternet.org/2012/03/19/teenssmartphones-texting/

Light, B. (2014). Disconnecting with Social Networking Sites. Basingstoke: Palgrave Macmillan.

Ling, R. (2016). Soft coercion: Reciprocal expectations of availability in the use of mobile communication. First Monday, 21(9), doi:10.5210/fm.v21i9.6814 
Morrison, S. L., \& Gomez, R. (2014). Pushback: Expressions of resistance to the "evertime" of constant online connectivity. First Monday, 19(8). doi:

10.5210/fm.v19i8.4902 


\title{
COOL REFUSAL: REJECTING DIGITAL TECHNOLOGY IN LATE CAPITALISM
}

\author{
Magdalena Kania-Lundholm \\ Uppsala University, Sweden
}

This paper asks what it means to disconnect from online media in a society where networked digital technologies (ICTs), including social media, permeate all spheres of social life. More specifically, it explores the notion of online disconnection, also referred to as media refusal (Portwood-Stacer, 2012). Disconnection here is understood as both disconnection from particular digital devices or social media platforms as well as the broader discourse about whether people have a 'right to disconnect'. These forms of disconnection exist in relation to connection as a possibility (Light, 2014, Hesselberth, 2017). They are also responses to the culture of connectivity - of being 'always on'that results in so-called information fatigue and overload, and is linked to an array of concerns about people's health and well-being. Due to growing pressures to resist the culture of connectivity, individuals are increasingly expected to manage and restrict their connections, often through practices of online disconnection.

In this paper, I locate the practices and discourses of disconnection within the context of cool capitalism defined as the "incorporation of disaffection into capitalism itself" which constitutes the front region of neoliberal culture (McGuigan, 2009). Cool capitalism refers to the cultural aspects of the current dominant, post-Fordist model of capitalism and can be understood as transition from the mid-twentieth century organized capitalism to the global neoliberal capitalism. This transition can also be understood in terms of the changing role between technology and society and the shifting relationship between humans and technology. The previously dominant industrial technology was mainly legitimized by instrumental rationality and technological reason (Habermas, 1970 ) and was at the center of social planning, control and progress. However, the rise of digital, networked technologies marked the emergence of the "new spirit of capitalism" and the "connexionist world" (Boltanski and Chiapello, 2005). Such a shift also placed technology at the center of individual empowerment and emancipation. The transition from organized capitalism and industrial technology towards global neoliberal capitalism and networked technology has contributed to shifting conceptualisations of the relationship between humans and technology. While the industrial period can be described in terms of utilitarian "man versus machine" logic, the current period is marked by a networked logic that is characterized by a flattened and non-hierarchical distinction between humans and technology (Fisher, 2010). In this context, technology receives an elevated status. It is framed by the techno-rational and techno-deterministic discourses that view technology not only as beneficial, but also as inevitable and desireable. In this context, emerging individual models of achievement, especially for young people, include the ideal of the neoliberal self, which combines the entrepreneurial spirit with consumer sovereignty (McGuigan, 2014).

I argue that, similar to the way cool became incorporated into everyday life and global neoliberal capitalist mainstream, cool refusal is an ideology not just about media resistance (Syvertsen, 2017), but is also a culturally and historically specific moment of 
individual coping in the era of neoliberal hyperconnectivity. The ideology of cool refusal is underpinned by a logic that encompasses three main interconnected aspects of social life: lifestyle choices, workplace strategies, and consumption patterns. This is to say that coolness is strived for and achieved mainly through conspicuous consumption of disconnective and/or analogue devices and conspicuous non-consumption of online media (Portwood-Stacer, 2012, Thorén et al, 2017). Consequently, it becomes incorporated into the cultural mainstream in a manner similar to the way that notions of authenticity, self-empowerment and individuality inform the neoliberal self. In this way, for instance, temporary quitting of social media can be understood not as a political act but rather as self-management technique aiming to achieve higher productivity and efficiency (Fish, 2017, Sutton, 2017). The logic of cool refusal implies that the acts of seemingly resistive and disaffected potential become incorporated in the capitalist modus operandi. By proposing the concept of cool refusal, and analysing its underlying logics, this paper aims to contribute to the rapidly growing body of research that makes an attempt to understand online disconnection and media refusal as an inherent element of media (dis)engagement in the digital age.

Finally, I suggest that in the context where disconnection is increasingly commodified and omnipresent, disconnection is becoming 'the new luxury' that only some can afford. This is especially the case in contexts where connection comes at the price of compromising one's privacy and autonomy, which are increasingly subjecting to corporate power and data exploitation (Karppi, 2018, Couldry \& Meijas, 2019). The question of whether "the right to disconnect" becoming new type of privilege will produce new forms of social and digital exclusion remains open for scholarly investigation.

\section{References}

Boltanski, L. Chiapello, E. (2005). The New Spirit of Capitalism. London: Verso

Couldry, N., Meijas, C. (2019). The Cost of Connection. How Data is Colonizing Human Life and Appropriating it for Capitalism. Stanford: Stanford Univ. Press

Fish, A. (2017). Technology Retreats and the Politics of Social Media. TripleC, 15(1), 355-369.

Fisher, E. (2010). Media and capitalism in digital age: The Spirit of Networks. New York: Palgrave

Habermas, J. (1970). Technology and Science as "Ideology", in: Toward a Rational Society. Boston: Beacon Press

Hesselberth, P. (2017). Discourses on disconnectivity and the right to disconnect, New Media \& Society, 20(5), 1994-2010.

Karppi, T. (2018). Disconnect. Facebook's Affective Bonds. Minnesota Univ. Press

Light, B. (2014). Disconnecting with Social Networking Sites. Palgrave Macmillan 
McGuigan, J. (2009). Cool Capitalism. London: Pluto Press

McGuigan,J. (2014). The Neoliberal Self. Culture Unbound, (6): 223-240.

Portwood-Stacer, L. (2012). Media refusal and conspicuous non-consumption: The performative and political dimensions of Facebook abstention. New Media \& Society (5), $1-17$.

Sutton, T. (2017). "Disconnect to reconnect: The food/technology metaphor in digital detoxing", First Monday, 22(6).

Syvertsen , T. (2017). Media Resistance. Protest, Dislike, Abstention. London: Palgrave Macmillan

Thorén, C., Edenius, M., Eriksson Lundström, J., Kitzmann, A. (2017). The hipster's dilemma: What is analogue or digital in the post-digital society? Convergence: The International Journal of Research into New Media Technologies, online first. doi: 10.1177/1354856517713139 


\title{
SETTING YOUR OWN TEMPO: DISCONNECTIVE FEATURES THAT ENABLE DIGITAL DISENGAGEMENT
}

\author{
Alex Beattie \\ Victoria University of Wellington, New Zealand
}

This paper responds to Bivens and Hasinoff's (2018) call to uncover technology features that resist dominant structural systems. The 'attention economy' is a dominant socio-economic system underpinning digital technology that degrades user trust by driving undesirable hyper-connectivity. At a micro-level, the attention economy incentivizes software developers to create habitual technological experiences that glues users to their screens (Alter, 2017). At a macro-level, the attention economy commoditizes user attention and reorganizes the internet into a persuasive advertising platform (Wu, 2016). Moreover, the attention economy purportedly amplifies arduous communicative norms, such as Fear of Missing Out (FoMO) and the burden of constant availability (Lanier, 2018) which has been linked to increased rates of loneliness, anxiety or depression (Reer et al., 2019) and losses in focus and productivity (Carr, 2011; Foot, 2014).

I offer an empirical investigation of 'disconnective features'--technical features that resist the attention economy and disconnect users from the internet-and 'disconnective technologies' - internet jammers, productivity applications or technologies that disconnect users from the internet. While disconnective features and technologies, prima facie, appear to be oxymoronic by requiring users to connect to technology in order to disconnect from technology (Hesselberth, 2018), I position disconnective features and technologies as extensions of what Ben Light (2014) calls 'disconnective practices': actions within the network (such as unfollowing someone on Facebook) that untie users from connective possibilities when using networked information communication tools. I analyse a disconnective technology called Siempo, an Android launcher application that aims to break smartphone addiction and reform the attention economy. Co-founded by social entrepreneur and technology designer Andrew Dunn, Siempo offers several disconnective features that enable users to disconnect from their device. In this paper I ask: what disconnective features does Siempo deploy to facilitate user disconnection from the network, and secondly, what are the cultural implications when disconnection is technically produced or enabled via a smartphone application?

Using a mix of the walkthrough method (Light et al., 2016) and a semi-structured interview undertaken with Siempo co-founder Andrew Dunn in September 2018, I outline two disconnective features of Siempo. The first is batched notifications: a software protocol that disconnects the user by customizing Do Not Disturb functionalities to delay the transmission of information across the network and ensure the end user receives notifications on a 'tempo' or schedule of their choice. Batched notifications represent an interactive aspect of software that has largely been overlooked by media studies. Recent application or platform studies approaches (see Helmond, 2015; Dieter et al., 2018) suggest network connections as entry points to studying software applications. By analysing a disconnective feature such as batched 
notifications, I reveal the opposite: the nuances in which network connections can be severed, delayed, or otherwise disconnected for the benefit of the end user. This offers an alternative perspective on software functionalities-one that captures instances where people seek refuge from networks or even desire network infrastructure to temporarily fail. This perspective opens up new possibilities for a more comprehensive and critical approach to platform and infrastructure studies.

The second disconnective feature I describe as 'plain packaging', where iconography, branding, and other cues that encourage the use of flagged or 'addictive' applications are stripped from the interface. Addiction experts justify plain packaging on the basis that branding on cigarette packets appropriates people's attention and primes them to keep smoking (Wakefield et al., 2013). The plain-packaging of the Siempo interface draws upon similar psychology to create a uniform and dull interface designed to disincentivize smartphone use. To this end, I argue that Siempo reveals two distinct modes of disconnective features: an actual intrusion between connections on the internet, and a fabrication of disconnection, where no interference with network connections is undertaken, but rather, users are incentivized to disconnect from their device by the deployment of psychological design.

The use of psychological design to fabricate disconnection shifts the operation of disconnection onto the end user. There are, however, implications when incentivizing disconnection via self-management techniques. As a technology of the self (Foucault, 1988) Siempo encourages users to manage themselves as self-regulated and autonomous but, critically, productive agents. The cultural implications of disconnection via a technology of the self, I argue, is the transformation of disconnection into something that is less to do with breaking connections per se, and more about the redirection of online behavior for productive or healthy purposes, or otherwise selfoptimal ends. More broadly, a consequence of self-regulating smartphone behavior is the individualisation of the social problem of the attention economy and associated pervasive digital distractions.

\section{References}

Alter, A. (2017). Irresistible: Why We Can't Stop Checking, Scrolling, Clicking and Watching. London: The Bodley Head.

Bivens, R. \& Hasinoff, A. A. (2018). Rape: is there an app for that? An empirical analysis of the features of anti-rape apps. Information, Communication \& Society. 21(8), 1050-1067.

Carr, N. (2011). The Shallows: What the Internet Is Doing to Our Brains. New York: W. W. Norton \& Company.

Dieter, M., Gerlitz, C., Helmond, A., Tkacz, N., van der Vlist, F. \& Weltevrede, E. (2018). Store, interface, package, connection Methods and propositions for multi-situated app studies [white paper] Working Paper Series, no. 4, August 2018, Collaborative Research Center 1187 Media of Cooperation, Retrieved from https://www001.zimt.unisiegen.de/ojs/index.php/wps1187/article/view/29 
Foot, K. (2014). The Online Emergence of Pushback on Social Media in the United States: A Historical Discourse Analysis. International Journal of Communication, 8 , 1313-1342.

Foucault, M. (1988). Technologies of the Self. In: L. H. Martin, H. Gutman \& P. H. Hutton (eds.), Technologies of the Self: A Seminar with Michel Foucault. Amherst: The University of Massachusetts Press, 16-49.

Hesselberth, P. (2018). Discourses on disconnectivity and the right to disconnect. New Media \& Society, 20(5), 1994-2010.

Helmond, A. (2015). The Platformization of the Web: Making Web Data Platform Ready. Social Media + Society. doi: 10.1177/2056305115603080

Lanier, J. (2018). Ten Arguments For Deleting Your Social Media Accounts Right Now. London: The Bodley Head.

Light, B. (2014). Disconnecting with Social Networking Sites. Houndmills, Basingstoke: Palgrave MacMillan.

Light, B., Burgess, J. \& Duguay, S. (2016). The Walkthrough Method: An approach to the study of apps, New Media \& Society, 20(3), 881-900.

Reer, F., Tang, W. Y., \& Quandt, T. (2019). Psychosocial well-being and social media engagement: The mediating roles of social comparison orientation and fear of missing out. New Media \& Society, online first: doi: 10.1177/1461444818823719

Wakefield, M. A., Hayes, L., Durkin, S. \& Borland, R. (2013). Introduction effects of the Australian plain packaging policy on adult smokers: a cross-section study, BMJ Open, 3(7). doi: 10.1136/bmjopen-2013-003175

Wu, T. (2016). The Attention Merchants: The Epic Scramble to Get Inside Our Heads. New York: Alfred A. Knopf. 